\title{
Retraction Note: Study on mountain landslide distribution characteristics and 3D printing and its performance based on human machine interaction network
}

\author{
Wangjun $\mathrm{Mu}^{1} \cdot$ BingChen $\mathrm{Gou}^{2}$
}

Published online: 25 November 2021

(c) Saudi Society for Geosciences 2021

Retraction Note: Arabian Journal of Geosciences (2021) 14: 1381

https://doi.org/10.1007/s12517-021-07749-1

The Editor-in-Chief and the Publisher have retracted this article because the content of this article is nonsensical. The peer review process was not carried out in accordance with the Publisher's peer review policy. The authors have not responded to correspondence regarding this retraction.

The original article can be found online at https://doi.org/10.1007/ s12517-021-07749-1.

Wangjun $\mathrm{Mu}$

junjushi.8336@163.com

1 Department of Aeronautical Engineering, Shaanxi

Polytechnic Institute, Xianyang 712000, Shaanxi, China

2 School of Mechanical Engineering, Northwestern

Polytechnic University, Xian 710072, Shaanxi, China 